\title{
Pemantauan Tegangan Baterai Lithium Polymer pada Robot Line Follower secara Nirkabel
}

\author{
Ricky Irawan Putra ${ }^{1}$, Sunardi $^{2}$, Riky Dwi Puriyanto ${ }^{3}$
}

Program Studi Teknik Elektro, Universitas Ahmad Dahlan, Indonesia

Kampus 4 Jl. Ringroad Selatan, Kragilan, Tamanan, Kec. Banguntapan, Bantul, Daerah Istimewa Yogyakarta 55191

\begin{tabular}{l}
\hline INFORMASI ARTIKEL \\
\hline Riwayat Artikel: \\
Dikirimkan 29 Juli 2019, \\
Direvisi 10 Agustus 2019, \\
Diterima 05 September 2019. \\
\hline Kata Kunci: \\
Arduino Uno, \\
Bluetooth HC-05, \\
Pemantauan Tegangan, \\
App Inventor, \\
Aplikasi Android. \\
\end{tabular}

Penulis Korespondensi:

Ricky Irawan Putra, Program Studi Teknik Elektro, Universitas Ahmad Dahlan Purwodadi 02/01Purworejo, Indonesia Surel: Ricky.ip97@gmail.com

\begin{abstract}
ABSTRAK
Dalam penelitian ini dirancang suatu sistem pemantauan kondisi tegangan baterai secara otomatis dengan tujuan dapat mempermudah pengguna dalam mengetahui tegangan baterai. Sistem yang dibangun dalam penelitian ini dibagi menjadi 2 bagian yaitu sistem pembacaan data dan sistem komunikasi nirkabel. Dalam sistem pembacaan data menggunakan sensor tegangan dan Arduino Uno sebagai pengolah data, lalu modul Bluetooth HC-05 sebagai media pengirim data ke smartphone. Pada sistem komunikasi nirkabel memanfaatkan Bluetooth serta smartphone Android sebagai media penampil data hasil pembacaan. Sistem pemantauan tegangan baterai lithium polymer menampilkan informasi tentang kondisi tegangan baterai yang dapat dilihat pada smartphone Android. Sistem pemantauan tegangan telah berhasil mendeteksi tegangan pada baterai dengan variasi nilai PWM dengan motor DC sebagai beban. Nilai error tegangan pada PWM 50, PWM 150 dan PWM 255 adalah 0,$134 ; 0,338$; dan 0,326 . Sementara nilai standar deviasi adalah 0,$180555 ; 0,183848 ; 0,115758$. Hal tersebut menunjukkan alat dapat bekerja dengan baik dan memiliki tingkat akurasi pembacaan yang baik di bawah 0,4 volt.

In this study, a battery voltage condition pemantauan system was designed automatically with the aim of making it easier for users to find out the battery voltage. The system built in this study is divided into 2 parts, namely the data reading system and the wireless communication system. In the data reading system uses a voltage sensor and Arduino Uno as a data processor, then the Bluetooth HC-05 module as a data sender to the smartphone. In a wireless communication system utilizing Bluetooth and Android smartphones as a media viewer of reading data. Lithium polymer battery voltage pemantauan system displays information about battery voltage conditions that can be seen on an Android smartphone. The voltage pemantauan system has succeeded in detecting the voltage on the battery with a variation of the PWM value with a DC motor as a load. The voltage error values at PWM 50, PWM 150 and PWM 255 are $0.134 ; 0.338$; and 0.326 . While the standard deviation is 0.180555 ; $0.183848 ; .115758$. This shows the tool can work well and has a good reading accuracy level below 0.4 volts.
\end{abstract}

This work is licensed under a Creative Commons Attribution-Share Alike 4.0

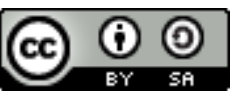

\section{Sitasi Dokumen ini:}

R. I. Putra, S. Sunardi, and R. D. Puriyanto, "Pemantauan Tegangan Baterai Lithium Polymer pada Robot Line Follower secara Nirkabel,” Buletin Ilmiah Sarjana Teknik Elektro, vol. 1, no. 2, pp. 73--81, 2019. DOI: $\underline{10.12928 / \text { biste.v1i2.907 }}$

\section{PENDAHULUAN}

Perkembangan teknologi robotika saat ini telah mampu berperan dalam membantu aktivitas kehidupan manusia serta mampu meningkatkan kualitas maupun kuantitas berbagai industri. Teknologi robot juga dimanfaatkan sebagai media pembelajaran, hobi, hiburan dan penelitian-penelitian robotika. Line follower adalah robot yang bisa bergerak mengikuti jalur panduan garis [1]. Garis pandu atau lintasan yang digunakan dalam hal ini adalah garis hitam yang ditempatkan pada permukaan berwarna putih, ataupun sebaliknya, garis putih yang ditempatkan pada permukaan berwarna hitam [2]. 
Berbicara mengenai perangkat elektronik maupun robot tentu tidak terlepas dari kebutuhan daya sebagai sumber utama penggerak perangkat tersebut. Penggunaan baterai merupakan kunci berhasil atau tidaknya suatu robot line follower dapat beroperasi. Tidak seperti pada mobil konvensional yang mana keberadaan baterai digunakan untuk menghidupkan alat-alat elektronik dalam mobil seperti radio lampu maupun pengatur suhu, tetapi pada robot line follower baterai berfungsi menjalankan mesin utama [3].

Pada peralatan elektronik khususnya pada motor penggerak maupun baterai sangat diperlukan suatu sistem pemantauan secara otomatis karena dengan sistem ini seluruh penggunaan energi dari motor penggerak dapat diketahui [4]. Pemantauan didefinisikan sebagai suatu kegiatan yang mencakup pengumpulan, peninjauan ulang, pelaporan dan tindakan atas informasi suatu proses yang sedang diimplementasikan [5].

Baterai Lithium Polymer (Li-Po) hampir sama dengan baterai Li- Ion akan tetapi baterai Li-Po tidak menggunakan cairan sebagai elektrolit melainkan menggunakan elektrolit polimer kering yang berbentuk seperti lapisan plastik film tipis. Parameter baterai Lithium Polymer (LiPo) sering kali kita melihat label di baterai yang disimbolkan dengan "S". Disini S berarti "sel" yang dimiliki sebuah paket baterai (battery pack). Sedangkan bilangan yang berada di depan simbol menandakan jumlah sel, dan biasanya berkisar antara 2-6S [6].

Terdapat juga kekurangan dari baterai Lithium Polymer yaitu, lemahnya aliran pertukaran ion yang terjadi melalui elektrolit polimer kering. Hal ini menyebabkan penurunan pada charging dan discharging rate [7]. Hal ini akan mempengaruhi tingkat tegangan yang dihasilkan oleh baterai [8].

Berdasarkan permasalahan tersebut, untuk dapat memecahkan masalahnya maka penulis merancang suatu sistem yang dapat memantau tegangan baterai Lithium Polymer menggunakan mikrokontroller berbasis arduino secara nirkabel. Sensor dipasang pada Baterai yang diberi beban robot line follower untuk mendeteksi tegangan, data akan dikirimkan ke mikrokontroler untuk proses dan dikirimkan melalui Bluetooth untuk ditampilkan pada Smartphone Android. Oleh karena itu dari uraian tersebut, penulis akan merancang Tugas Akhir yang berjudul, "Pemantauan Tegangan Pada Robot Line Follower secara Nirkabel".

\section{METODE PENELITIAN}

Objek penelitian ini adalah baterai Lithium Polymer 12V 1300mAh yang terdapat pada robot Line Follower sebagai beban kerjanya. Variabel yang diukur adalah nilai tegangan dengan nilai PWM yang bervariasi. Pada penelitian ini hal ini merupakan kunci dari penelitian dikarenakan seiring berubahnya nilai PWM maka nilai tegangannya dari baterai Lithium Polymer pun ikut berubah.

\subsection{DESAIN SISTEM}

Perancangan perangkat keras dan program dalam pemantauan tegangan dan berbasis Arduino Uno ini dibuat dalam bentuk diagram blok yang dapat dilihat pada Gambar 1. Diagram blok tersebut yang akan membantu penulis dalam melakukan perancangan.

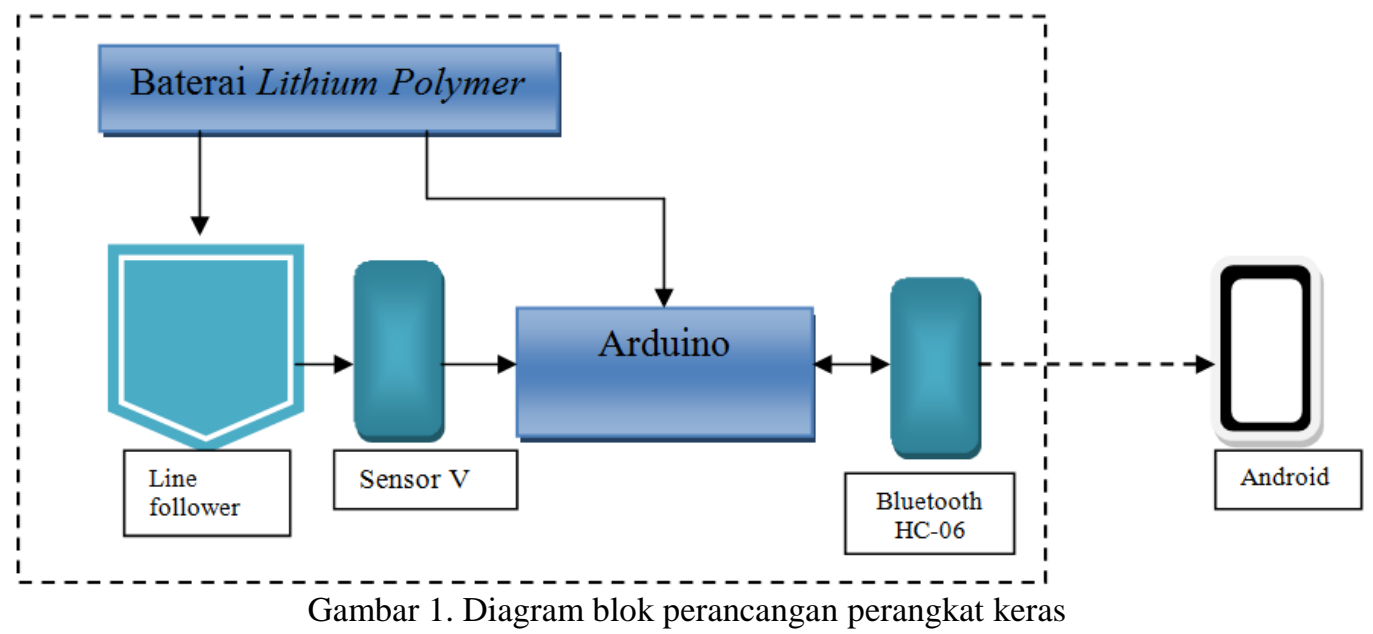

Pada diagram blok Gambar 1 memiliki 3 bagian utama yaitu masukan, mikrokontroler dan keluaran. Pada bagian masukan terdiri dari sebuah sensor tegangan yang berfungsi membaca data tegangan dari baterai Lithium Polymer. Data tersebut diterima oleh mikrokontroler dan merupakan data analog yang kemudian dikonversi menjadi suatu data digital menggunakan fitur ADC pada Arduino Uno. Data digital tersebut kemudian dikirim melalui Bluetooth HC-06 ke Smartphone Android yang menampilkan nilai keluaran dari keseluruhan perakitan sistem perangkat keras. 
Penggunaan modul Bluetooth HC-05 dengan frekuensi 2,4Ghz yang memudahkan dalam proses transfer data [9]. Selain itu menawarkan fitur yang baik untuk teknologi mobile wireless dengan biaya yang relatif rendah, konsumsi daya yang rendah, interoperability yang menjanjikan, mudah dalam pengoperasian dan mampu menyediakan layanan yang bermacam-macam [10].

Perangkat Arduino Uno, sensor tegangan dan modul Bluetooth HC-05 dirakit menjadi suatu sistem sehingga dapat membaca nilai tegangan dan menampilkan hasilnya pada smartphone Android. Rangkaian keseluruhan sistem dapat dilihat pada Gambar 2.

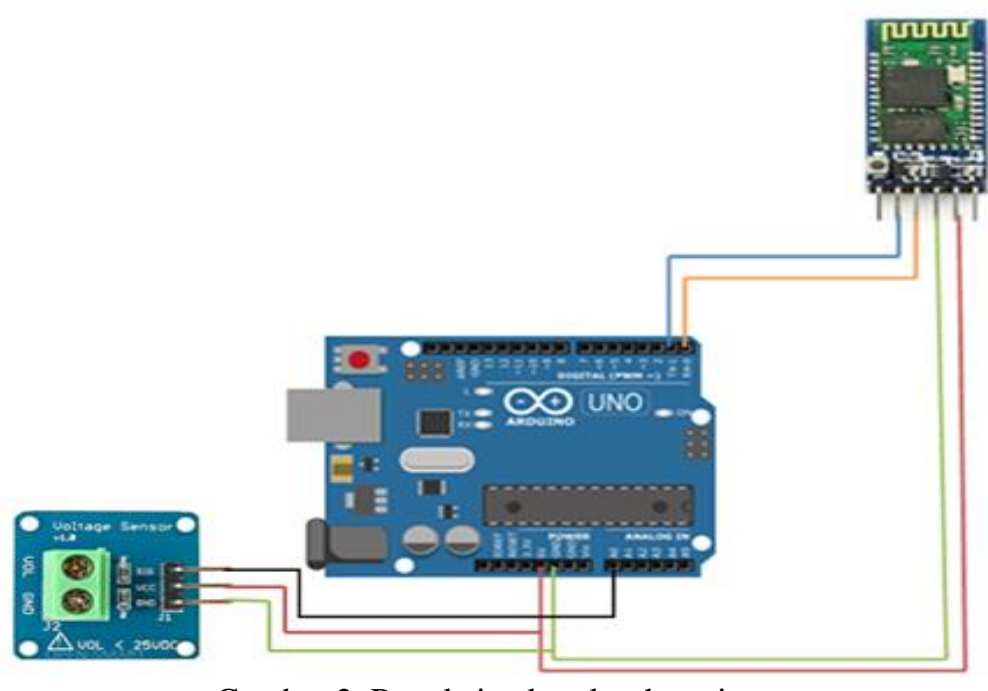

Gambar 2. Rangkaian keseluruhan sistem

\subsection{ALGORITMA}

Pada kode program yang diunggah ke mikrokontroler Arduino merupakan program untuk menerima data pembacaan sensor tegangan dan mengirimkan data tersebut melalui Bluetooth HC-05 ke smartphone Android. Pada listing program kode pembacaan sensor merupakan barisan kode untuk membaca nilai analog dari sensor tegangan. Kode program pembacaan sensor dapat dilihat pada Listing 1.

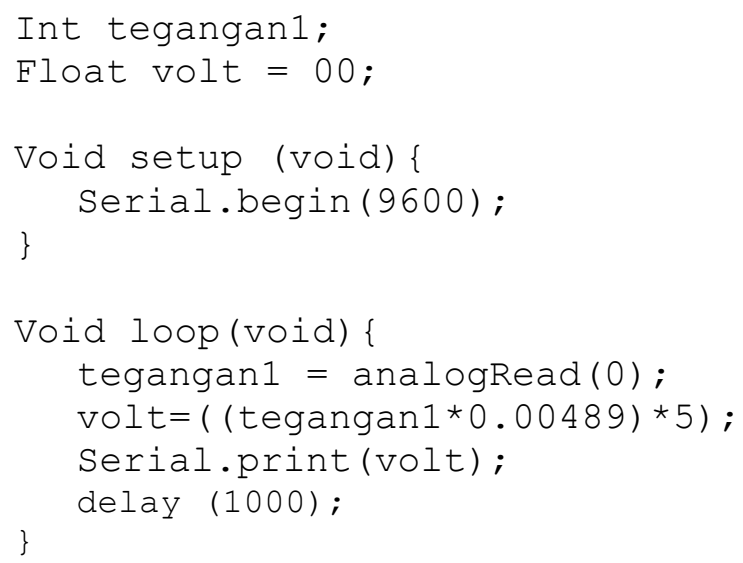

Listing1. Kode Program Pembacaan Sensor

Pada Listing 1 merupakan kode program untuk menginisialisasi pin A0 pada Arduino yang berfungsi membaca analogRead atau nilai analog yang di dapat dari sensor tegangan, sedangkan tegangan1 membaca nilai analog dengan tegangan maksimal yang dapat dibaca sebesar $25 \mathrm{~V}$ atau jika dalam nilai analog sebesar 1023, sedangkan pada penelitian ini baterai yang digunakan memiliki nilai tegangan sebesar $12 \mathrm{~V}$ yang dimana jika dikonversi ke nilai analog sebesar 204,6. Sehingga didapatkan hasil perhitungan seperti yang terlihat pada listing 3.1 hal ini bertujuan untuk mendapatkan nilai tegangan baterai yang sesuai dengan nilai yang terbaca pada multimeter sebagai parameter pembanding dalam penelitian ini..

Kode program komunikasi Android merupakan kode program yang berfungsi sebagai transmisi data dari alat pemantauan tegangan baterai ke Android. Kode program dapat dilihat pada Listing 2. 


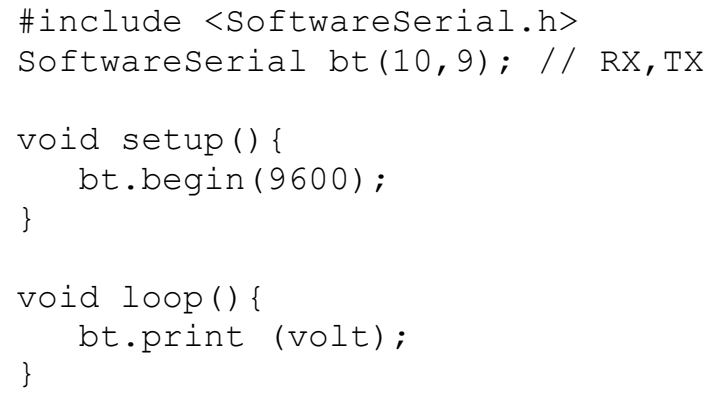

Listing 2. Program Bluetooth HC-05

Pada Listing 2 Program SoftwareSerial di atas berfungsi untuk menjadikan PIN 10 (RX) sebagai penerima dan pin 9 (TX) sebagai pengirim. Listing program bt.begin(9600) digunakan sebagai komunikasi serial untuk terhubung dengan Bluetooth HC-05 dan kecepatan aliran data menggunakan baudrate 9600 bps.

Pemrograman Arduino dilakukan untuk mengeksekusi perintah yang diinginkan pada rangkaian. Saat hardware diberi masukan berupa daya dari baterai lithium polymer mikrokontroler akan memulai proses inisialisasi input maupun output. Data yang masuk ke Arduino kemudian diolah dan dikirimkan melalui Bluetooth HC-05. Adapun bentuk Flowchart dapat dilihat pada Gambar 3.

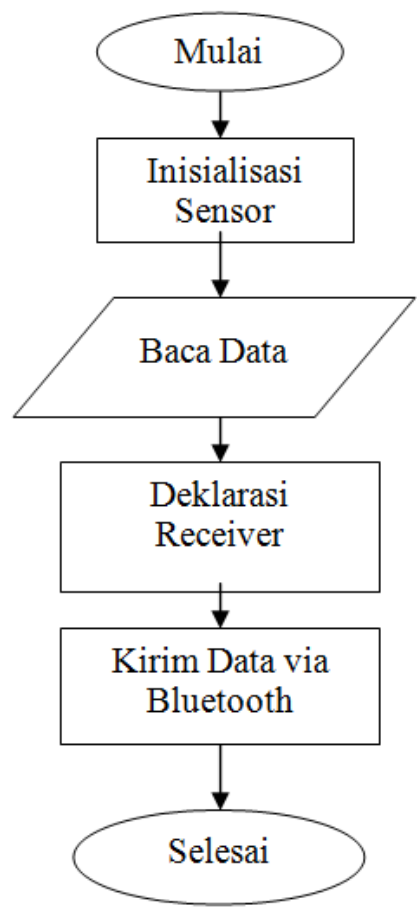

Gambar 3. Diagram alir sistem pemantauan

Ketika alat menerima catu daya yang berasal dari baterai Lithium Polymer, maka program akan memulai dan sensor akan berinisialisasi. Inisialisasi merupakan suatu proses persiapan untuk menentukan nilai awal yang digunakan. Pada waktu yang sama data dikirim ke android setelah receiver memberikan perintah. Ketika alat selesai digunakan maka program akan selesai.

\subsection{DESAIN PERANGKAT LUNAK}

Pada perancangan perangkat lunak penulis menggunakan Software App Inventor sebagai penyedia layanan pembuat aplikasi pada smartphone Android. Berikut adalah program perancangan aplikasi "Pemantauan Tegangan”. Berikut tampilan awal program pada Listing 3. 


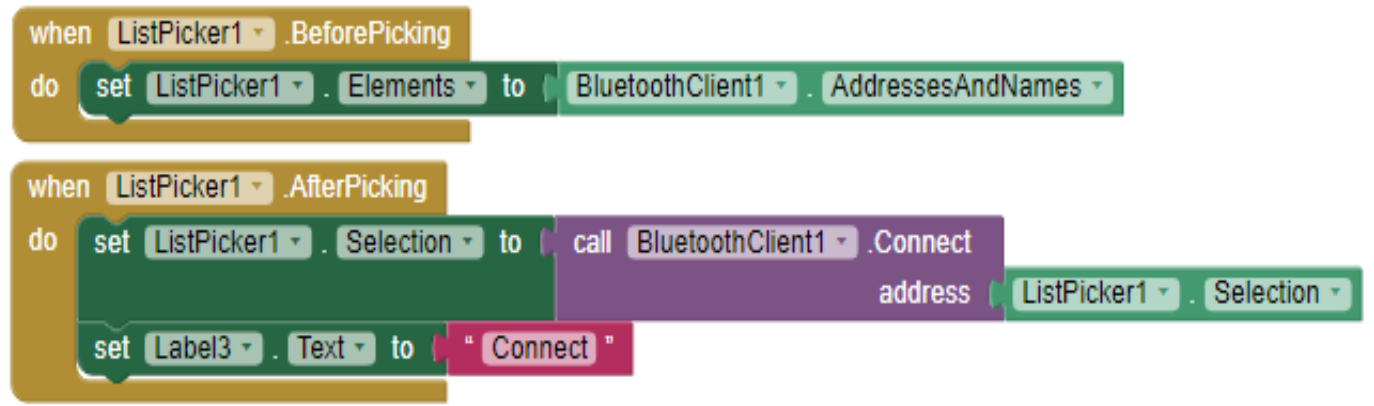

Listing 3. Tampilan awal program

Pada Listing 3 merupakan kode program untuk menghubungkan perangkat Bluetooth menggunakan fungsi dari Listpicker guna memilih perangkat Bluetooth mana yang dipilih. Ketika mode tersambung on maka label status pada tampilan aplikasi berubah menjadi connect. Dan ketika Buletooth sudah terhubung maka data yang diterima akan tampil pada aplikasi. Program dapat dilihat pada Listing 4.

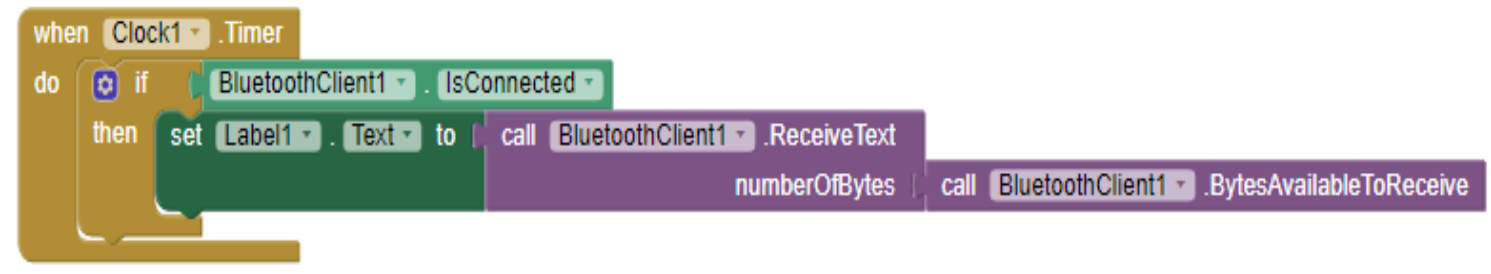

Listing 4. Kode program penerima Bluetooth

Pada Listing 4 berfungsi menerima data yang dikirmkan dari hardware melalui komunikasi Bluetooth sehingga dapat ditampilkan pada aplikasi Pemantauan Tegangan Baterai pada Android.

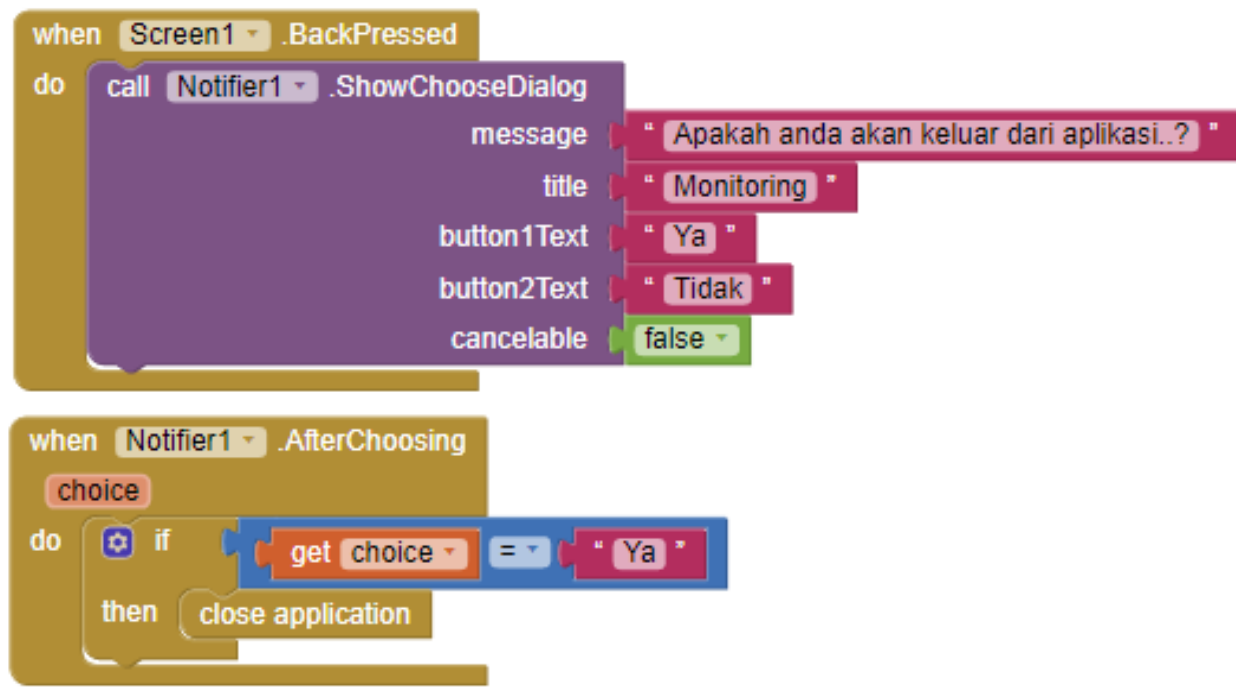

Listing 2. Kode menutup aplikasi

Pada Listing 5 merupakan kode program sebagai perintah ketika ingin keluar dari aplikasi moitoring tegangan baterai. Ketika tombol backpresed atau kembali ditekan maka akan muncul notifikasi berupa pesan yang bertuliskan "Apakah anda akan keluar dari aplikasi?" makan akan muncul pilihan berupa button "Ya" atau "Tidak".

\section{HASIL DAN PEMBAHASAN}

Pada pengujian alat Pemantauan Tegangan Baterai Lithium Polymer pada Robot Line Follower secara Nirkabel ini dilakukan dengan memanfaatkan sensor tegangan dan Aplikasi pada Smartphone Android sebagai media penampil datanya. 
Adapun alasan penggunaan Smartphone Android sebagai media dalam menampilkan hasil pemantauan data ialah kemudahan serta efektivitas dalam prosesnya, mengingat jika proses pemantauan dilakukan secara konvensional dengan menggunakan multimeter akan sulit dilakukan hal ini dikarenakan media yang akan dipemantauan merupakan suatu Robot yang bergerak sesuai perintahnya. Pengujian ini dilakukan dengan mengubah nilai PWM pada robot sebesar 50, 150, 255.Nilai yang terbaca oleh sensor kemudian dibandingkan dengan variabel pembandingnya yaitu multimeter.

\subsection{PENGUJIAN PWM 255}

Pengujian sensor tegangan baterai Lithium Polymer pada robot Line Follower berbasis Arduino secara nirkabel di atur dengan PWM 255 dengan maksud mengetahui perbedaan tegangan yang terjadi di setiap perubahan PWM-nya, adapun hasil yang didapat dari pengujian dengan set PWM 255 terlihat pada Tabel 1

Tabel 1. Hasil pengukuran dengan PWM 255

\begin{tabular}{ccc}
\hline Tegangan Sensor & Multimeter & Error \\
\hline 11,20 & 11,55 & 0,35 \\
\hline 11,22 & 11,54 & 0,32 \\
\hline 11,22 & 11,54 & 0,32 \\
\hline 11,20 & 11,54 & 0,34 \\
\hline 11,22 & 11,53 & 0,31 \\
\hline 11,22 & 11,53 & 0,31 \\
\hline 11,20 & 11,54 & 0,34 \\
\hline 11,20 & 11,54 & 0,34 \\
\hline 11,22 & 11,53 & 0,31 \\
\hline 11,22 & 11.54 & 0,32 \\
\hline Error rata-rata & 0,326 \\
\hline \multicolumn{2}{c}{}
\end{tabular}

Pengambilan data pada baterai lithium polymer dilakukan dengan waktu delay selama 2 detik hal ini didasari oleh penulis agar memudahkan dalam pengambilan data. Adapun grafik dari perbandingan hasil pengukuran dapat dilihat pada Gambar 4 berikut.

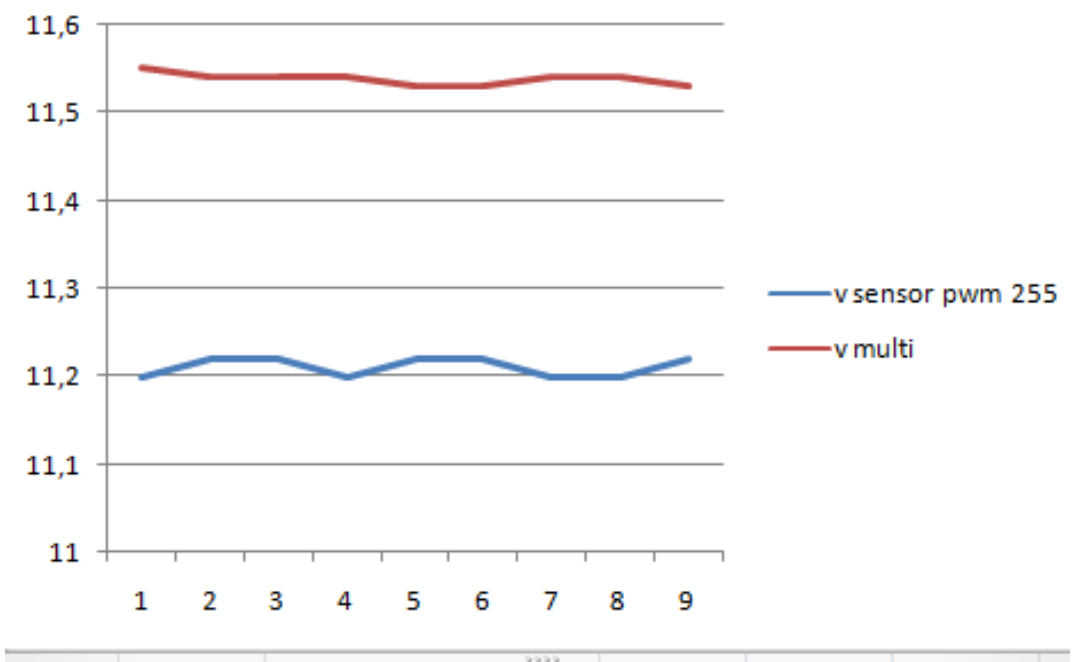

Gambar 4. Grafik Tegangan PWM 255

Dilihat dari Gambar 4 yang berupa Grafik perbandingan tegangan yang diukur pada baterai lithium polymer yang terkoneksi dengan beban berupa robot Line Follower serta sistem pemantauan masih terdapat selisih yang terjadi antara kedua metode pengukuran tersebut.

\subsection{PENGUJIAN PWM 150}

Dalam pengujian sensor selanjutnya robot line follower mengatur dengan PWM 150 untuk mengetahui perbedaan tegangan yang terjadi di setiap perubahan nilai PWM hal ini dimaksudkan agar dapat diketahui tingkat efektivitas penggunaan baterai berdasarkan nilai PWM-nya seperti pada Tabel 2.

Tabel 2. Pengujian sensor tegangan dengan PWM 150 


\begin{tabular}{ccc}
\hline Data Sensor & Multimeter & Error \\
\hline 11,22 & 11,53 & 0,31 \\
\hline 11,20 & 11,56 & 0,36 \\
\hline 11,17 & 11,55 & 0,38 \\
\hline 11,20 & 11,54 & 0,34 \\
\hline 11,22 & 11,54 & 0,32 \\
\hline 11,22 & 11,53 & 0,31 \\
\hline 11,22 & 11,54 & 0,32 \\
\hline 11,22 & 11,53 & 0,31 \\
\hline 11,17 & 11,54 & 0,37 \\
\hline 11,17 & 11,53 & 0,36 \\
\hline & Error rata-rata & 0,338
\end{tabular}

Berdasarkan data hasil pengamatan menggunakan sensor tegangan yang terhubung pada baterai lithium polymer didapatkan hasil grafik seperti yang terlihat pada Gambar 5.

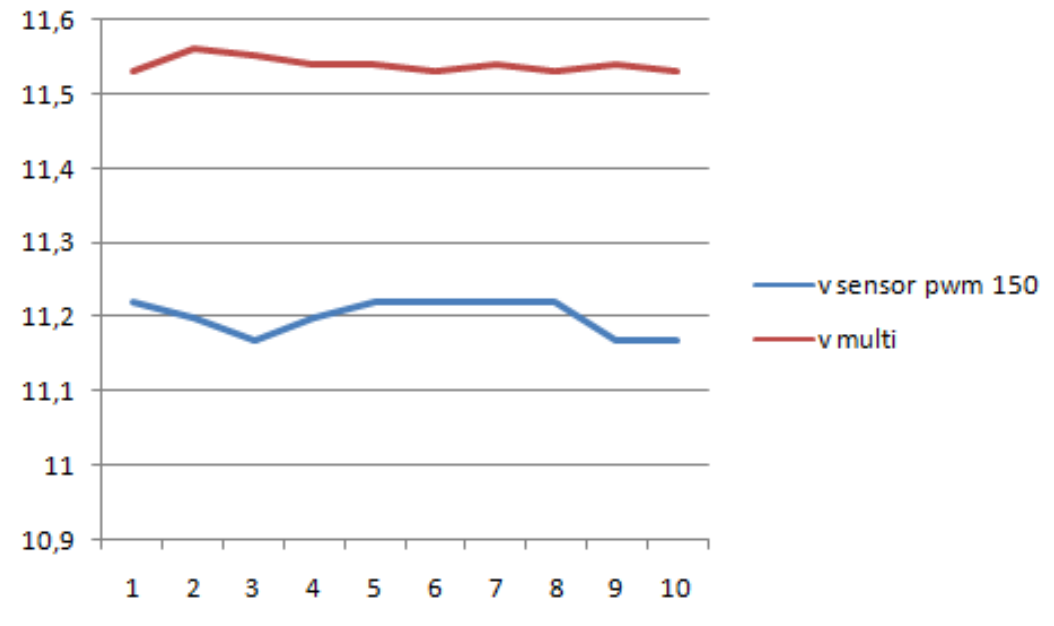

Gambar 6. Grafik tegangan PWM 150

\subsection{PENGUJIAN PWM 50}

Pada tahap pengujian selanjutnya dengan mengatur PWM pada angka 50 guna mengetahui perbandingan dari berbagai macam PWM baik dari nilai maksimal sebesar 255 hingga nilai minimal yang dilakukan dalam penelitian ini sebesar 50. Tabel 3 menunjukkan hasil pemantauan tegangan dengan nilai PWM sebesar 50.

Tabel 3. Data hasil pengujian sensor dengan PWM 50

\begin{tabular}{ccc}
\hline Data Pengujian & Multimeter & Error \\
\hline 11,03 & 11,53 & 0,23 \\
\hline 11,42 & 11,56 & 0,14 \\
\hline 11,42 & 11,55 & 0,13 \\
\hline 11,42 & 11,54 & 0,12 \\
\hline 11,42 & 11,54 & 0,12 \\
\hline 11,42 & 11,54 & 0,12 \\
\hline 11,42 & 11,54 & 0,12 \\
\hline 11,42 & 11,54 & 0,12 \\
\hline 11,42 & 11,54 & 0,12 \\
\hline 11,42 & 11,54 & 0,12 \\
\hline Error rata-rata & 0,134 \\
\hline
\end{tabular}

Berdasarkan data hasil pengamatan menggunakan sensor tegangan yang memanfaatkan resistor yang dibagi dengan tegangan resolusi Arduino Uno di dapatkan hasil grafik seperti yang terlihat pada Gambar 7. 


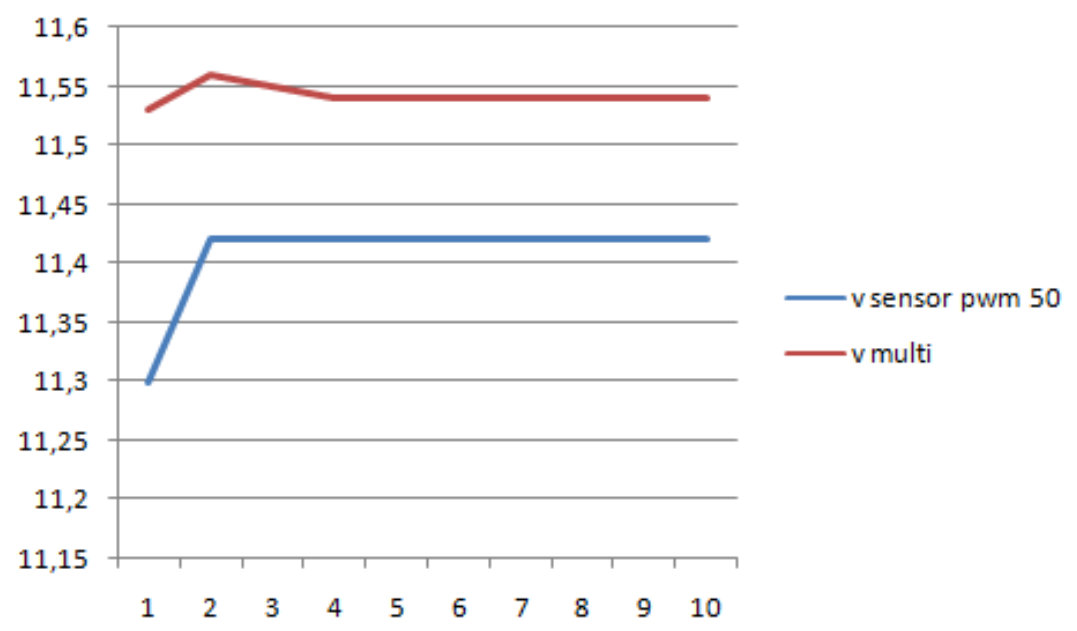

Gambar 7. Grafik hasil pengamatan tegangan dengan PWM 50

Berdasarkan percobaan yang telah dilakukan pengamatan atau pemantauan pada baterai lithium polymer yang diberi beban berupa robot line follower dengan nilai PWM yang berbeda-beda, diperoleh hasil nilai ratarata error dan standar deviasi yang dapat dilihat pada Tabel 4.

Tabel 4. Data hasil pengamatan keseluruhan

\begin{tabular}{ccc}
\hline PWM & Error rata-rata & Standar Deviasi \\
\hline 50 & 0,326 & 0,180555 \\
\hline 150 & 0,388 & 0,183848 \\
\hline 255 & 0,134 & 0,115758
\end{tabular}

Berdasarkan beberapa percobaan pengamatan tegangan baterai lithium polymer pada robot line follower secara nirkabel didapatkan beberapa hasil yang berbeda. Di antaranya pada percobaan dengan nilai PWM 50, error yang didapatkan berkisar pada nilai 0,326 . Pada percobaan dengan nilai PWM 150 error rata-rata yang diperoleh sebesar 0,388 dan pada percobaan dengan nilai PWM 255 didapatkan error rata-rata sebesar 0,134. Oleh karena itu, dapat disimpulkan bahwa proses pemantauan tegangan pada baterai lithium polymer berjalan dengan baik dengan kisaran error pada tiap percobaan mendekati nol.

Berdasarkan data yang telah diperoleh di setiap nilai PWM didapatkan nilai standar deviasi yang kecil hal ini sejalan dengan teori dasar bahwa semakin kecil standar deviasi maka akan semakin mendekati rata-rata. Oleh karena itu, penggunaan sensor tegangan pada penelitian ini memiliki rentang pembacaan yang baik.

\section{KESIMPULAN}

Berdasarkan hasil pengujian yang telah dilakukan berhasil dirancang suatu sistem pemantauan tegangan baterai lithium polymerpada robot line follower secara nirkabel dengan menggunakan Bluetooth sebagai komunikasinya serta smarphone Android sebagai media penampil hasil proses pemantauan. Sehingga didapatkan hasil error yang bervariasi dari beberapa percobaan dengan nilai PWM yang berbedabeda.Diantaranya percobaan dengan nilai PWM 50 didapatkan error sebesar 0,326 dan pada percobaan dengan nilai PWM sebesar 150 didapatkan hasil error sebesar 0,388 Serta pada pengaturan nilai PWM sebesar 255 didapati hasil error 0,134 . Hal ini dapat disimpulkan bahwa proses pemantauan dengan menggunakan sensor tegangan secara nirkabel berhasil dilakukan.

\section{UCAPAN TERIMA KASIH}

Terima kasih penulis ucapkan kepada editor dan reviewer atas semua saran dan masukannya hingga terselesaikan jurnal ini. Tak lupa penulis ucapkan terima kasih kepada semua pihak yang terkait dalam penyelesaian jurnal ini. Penulis mengharapkan agar tugas akhir ini dapat dimanfaatkan dengan sebaik-baiknya guna menambah ilmu pengetahuan bagi diri sendiri khususnya bagi para pembaca. 


\section{REFERENSI}

[1] Fatchuurrohman, A.F. (2014). "Robot Line Follower Pid Sebagai Media Pembelajaran Aplikasi Mikrokontroler Di Jurusan Pendidikan Teknik Elektronika”. Teknik Elektro UNY.

[2] Wahyudi, Hebi Jaya (2015). "Perancangan dan Realisasi Robot Line Follower untuk Pengangkut Sampah Otomatis". Universitas Telkom.

[3] Amir Hazah, R., Rusdinar, A., \& Nugraha, R. (2017). Implementasi Sistem Pemantauan Dan Manajemen Baterai Pada Kendaraan Listrik.

[4] Fitriandi, A., Komalasari, E., \& Gusmedi, H. (2016). Rancang Bangun Alat Pemantauan Arus dan Tegangan Berbasis Mikrokontroler dengan SMS Gateway. Rekayasa Dan Teknologi Elektro, hal 87-98.

[5] Prisma, A., Segara, B., Riawan, D. C., \& Suryoatmojo, H. (2013). Pemantauan Kinerja Baterai Berbasis Timbal untuk Sistem Photovoltaic, hal 1-6

[6] Harahap, F. A. (2017). Rancang Bangun Data Logger Pengukuran Arus, Tegangan dan Suhu Dari Suatu Baterai

[7] Ardyanto, B. (2019). "Pengukuran Tegangan, Arus dan Daya Listrik Menggunakan Perangkat Telepon Pintar".

[8] Bismaputra, Johanes (2017). "Rancang Bangung Sistem Pemantauan Tegangan Baterai pada Robot Pembersih Kaca Berbasis Wireless. Diploma Tesis. ITS.

[9] Yohannes, Asi. "Aksisi Data Alat Ukur Arus, Tegangan, Hambatan dan Suhu dengan Digital Konektivitas Bluetooth pada Ponsel Cerdas Android. Teknik Elektro. Universitas Diponegoro.

[10] Kurniansyah, S., \& Sriwijaya, P. N. (2017). Sistem Kerja Robot Pembersih Lantai Menggunakan Motor Dc Dan Sensor.

\section{BIOGRAFI PENULIS}

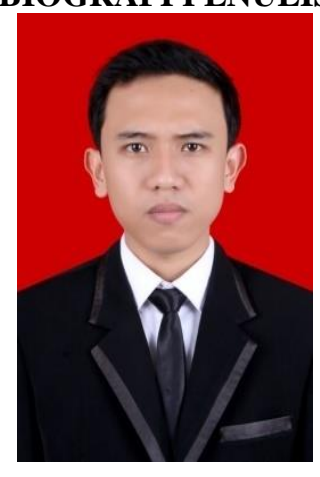

\section{Ricky Irawan Putra}

Lahir di Bandung tanggal 02 April 1997. Menyelesaikan pendidikan S1 Teknik Elektro di Universitas Ahmad Dahlan Yogyakarta.

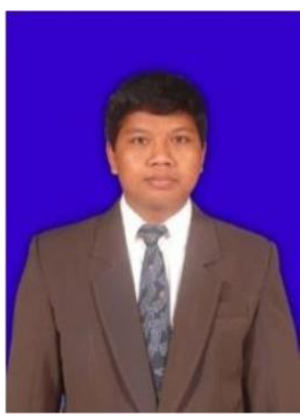

\section{Sunardi}

Lahir di Sragen tanggal 21 Mei 1974, Menyelesaikan pendidikan S1 Teknik Elektro di Universitas Gajah Mada Yogyakarta, S2 di Universitas Teknologi Bandung, dan S3 di Universitas Teknologi Malaysia. Bidang yang diminati beliau Wireless Communication. Saat ini beliau menjabat sebagai Dekan FTI Universitas Ahmad Dahlan Yogyakarta.

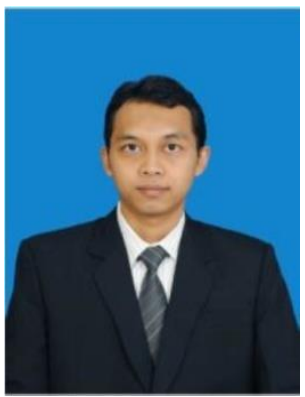

Riky Dwi Puriyanto

Lahir di Sukoharjo tanggal 4 Mei 1998, Menyelesaikan pendidikan S1 Teknik Elektro di Universitas Gajah Mada Yogyakarta dan S2 Teknik Elektro di Universitas Gajah Mada Yogyakarta. Bidang yang diminati beliau Renewable Energy \& Signal Processing. Saat ini beliau menjadi sekretaris program studi di Universitas Ahmad Dahlan Yogyakarta. 